Koga, E.S.; Oliveira, C.S.; Kaneshiro, D.M. Programa de capacitação do Projeto de Ecoturismo na Mata Atlântica no entorno dos parques estaduais paulistas. Revista Brasileira de Ecoturismo, São Paulo, v.6, n.1, jan/abr-2013, pp.255-268.

\title{
Programa de capacitação do Projeto de Ecoturismo na Mata Atlântica no entorno dos parques estaduais paulistas
}

\author{
Training program of the Ecotourism Project in the Atlantic Rain Forest \\ around state parks of São Paulo (Brazil)
}

\section{Érika Sayuri Koga, Caroline da Silva Oliveira, Daniela Midori Kaneshiro}

\begin{abstract}
RESUMO
Com o objetivo de consolidar a vocação do turismo sustentável em seis Parques Estaduais do Estado de São Paulo e suas regiões de entorno está em execução o Projeto de Desenvolvimento do Ecoturismo na Região da Mata Atlântica. Desenvolvido pela Secretaria do Meio Ambiente do Estado de São Paulo (SMA), por meio de um contrato firmado com o Banco Interamericano de Desenvolvimento (BID) é uma estratégia de conservação da natureza e apoio ao desenvolvimento socioeconômico regional. Este artigo apresenta os resultados relacionados ao programa de capacitações dos diferentes atores da região do entorno dos parques do Vale do Ribeira, Alto Paranapanema e Ilhabela. O programa de qualificação do Projeto de Ecoturismo, calcado no processo participativo das comunidades, nas parcerias junto às ONGs, micro e pequenos empresários, Prefeituras e Secretarias Municipais atingiu o objetivo de organizar e consolidar o produto turístico na área de influência direta do Projeto, procurando incrementar novos negócios, gerar renda e emprego na região.
\end{abstract}

PALAVRAS-CHAVE: Unidade de Conservação; Parque Estadual; Capacitação; Ecoturismo; São Paulo.

\begin{abstract}
With the main goal to consolidate the vocation of sustainable tourism in six State Parks of São Paulo (Brazil) and their surrounding regions, there are running the Project Development of Ecotourism Mata Atlantica. Developed by the Secretariat for Environment of the State of São Paulo (SMA), through a contract with the Interamerican Development Bank (IDB) is a strategy for nature conservation and support for regional socioeconomic development. This paper presents the results related to the qualification program of different actors in the surrounding area of the parks in the Vale do Ribeira, Alto Paranapanema and Ilhabela. The qualification program of the Ecotourism Project, based in the participatory process of communities, in partnerships with NGOs, Municipalities, entrepreneurs and Municipal Secretariat reached the goal of organizing and strengthening the tourism product in the area of direct influence of the Project, seeking to increase new business, generate income and employment in the region.
\end{abstract}

KEYWORDS: Protected Areas; State Park; Training; Ecotourism; São Paulo.

Página 255 Revista Brasileira de Ecoturismo, São Paulo, v.6, n. I, jan/abr 2013, pp.255-268.

Sociedade Brasileira de Ecoturismo. Rua Dona Ana, 138, Vila Mariana, São Paulo, SP - Brasil. E-mail: rbecotur@sbecotur.org.br; Tel. (55-II) 99196-7685 
Programa de capacitação do Projeto de Ecoturismo na Mata Atlântica no entorno dos parques estaduais paulistas

\section{Introdução}

A conservação de áreas naturais diante do avanço econômico e social é um desafio para a sustentabilidade. Alternativas de desenvolvimento que atrelem à conservação do meio ambiente devem ser promovidas. Nesse sentido, o Projeto de Desenvolvimento do Ecoturismo na região da Mata Atlântica no Estado de São Paulo está sendo executado pela Secretaria de Estado do Meio Ambiente, por meio de um contrato firmado com o Banco Interamericano de Desenvolvimento. O objetivo do Projeto é consolidar a vocação do turismo sustentável em sua área de influência como estratégia de conservação da natureza e apoio ao desenvolvimento socioeconômico da região. Para tanto, estão sendo desenvolvidas ações para organizar e consolidar as Unidades de Conservação como produtos turísticos com capacidade de atrair e satisfazer um mercado diverso de visitantes.

A área de abrangência do Projeto são seis Parques Estaduais localizados nas regiões do Vale do Ribeira, Alto Paranapanema e Litoral Norte de São Paulo. São eles: "Carlos Botelho", Intervales, Caverna do Diabo, Turístico Alto Ribeira (PETAR), Ilha do Cardoso e Ilhabela que englobam regiões contínuas de Mata Atlântica - um dos ecossistemas mais rico e ameaçado do mundo - reconhecida pela UNESCO como Reserva da Biosfera e Sítio do Patrimônio Natural da Humanidade.

As atividades planejadas pelo Projeto foram divididas em três componentes principais: (i) Estruturação dos parques para a visitação pública, com a implantação de novos serviços e estruturas, além da reorganização administrativa para maior eficiência, controle e incremento da satisfação dos visitantes; (ii) Organização e consolidação do produto turístico na área de influência direta do Projeto, envolvendo comunidades, pequenos empresários e prefeituras, procurando incrementar novos negócios e promover a estruturação da cadeia produtiva do turismo, gerando renda e emprego na região; e, (iii) Fortalecimento da gestão pública, incluindo uma nova política de ecoturismo para os parques, regras de visitação e controle, plano de capacitação de pessoal, monitoramento, entre outros.

Dentro do componente (ii) que está voltado para o fortalecimento da cadeia produtiva do turismo na área de entorno dos parques, o Projeto realizou um programa de qualificação de pessoas envolvidas na região dos Parques, no qual abordou três grandes grupos: gestores municipais responsáveis pelas pastas de turismo e/ou meio ambiente para qualificação quanto ao desenvolvimento e organização do turismo e integração regional; micro e pequenos empreendedores do segmento de turismo que já atuam na região de todos os Parques contemplados pelo Projeto e almejam requalificação de seus serviços; e, comunidades tradicionais comprometidas com atividades relacionadas direta e/ou indiretamente com o turismo, focando nas atividades potenciais para desenvolvimento socioeconômico das populações que vivem na região dos Parques Estaduais "Carlos Botelho", Intervales, Caverna do Diabo e PETAR, de forma a agregar suas produções à atividade turística.

As capacitações tiveram o objetivo geral de promover a melhoria da qualidade dos serviços prestados diretamente aos visitantes e promover o fortalecimento da cadeia produtiva do turismo na região do entorno dos Parques Estaduais, juntamente 
Koga, E.S.; Oliveira, C.S.; Kaneshiro, D.M.

com a própria Unidade de Conservação (UC).

O presente artigo tem o objetivo de relatar o programa de qualificação do Projeto de Ecoturismo, desde a concepção de temas, públicos-alvo e metodologia dos cursos. O relato transcorre para a execução das capacitações, finalizando com os resultados obtidos pelo programa.

O artigo descreve a região do Vale do Ribeira e Alto Paranapanema para entendimento das particularidades que caracterizam as UCs e região do entorno dos parques; prossegue com a fundamentação de ecoturismo e planejamento participativo que fundamentaram a formatação das capacitações; e, finaliza com os resultados obtidos e avaliações.

\section{As regiões do Vale do Ribeira e do Alto Paranapanema}

O Vale do Ribeira abrange a Bacia Hidrográfica do Rio Ribeira de Iguape e o Complexo Estuarino Lagunar de Iguape-Cananéia-Paranaguá. Apesar de ter sido uma das primeiras e mais exploradas regiões brasileiras nos períodos colonial e imperial, ainda guarda o maior remanescente de Mata Atlântica preservada do Brasil. Ou seja, dos $7 \%$ que restaram deste bioma no Brasil, $21 \%$ estão localizados no Vale do Ribeira (SANTOS, 2008).

A região do Alto Paranapanema extende-se por $22.689 \mathrm{~km}^{2}$, compreendendo a porção paulista da bacia hidrográfica do Alto Paranapanema. Um dos principais cursos d'água dessa região, além do próprio Paranapanema, é o rio Itararé que forma divisa entre os Estados do Paraná e São Paulo (CBH-ALPA, 2011).

Segundo Atlas geoambiental (THEODOROVICZ, 2007), o Vale do Ribeira destaca-se por ser uma região de relevos variados, um denso sistema de drenagem com formações de corredeiras, cachoeiras e piscinas naturais. Também é um dos pólos mais importantes de produção mineral do Brasil e onde ocorre grande concentração de cavernas calcária.

O Vale conta com uma população de cerca de 411.500 habitantes, mais da metade vivendo nas zonas rurais e envolve áreas entre duas importantes capitais São Paulo e Curitiba. Uma das principais vias de acesso à região é a Rodovia Régis Bittencourt (BR -116), que liga São Paulo ao Paraná.

Alguns conflitos ocorrem na região em função da urbanização, agricultura e a exploração de recursos naturais. Conforme Theodorovicz (2007, p.1),

algumas áreas com potencial turístico natural e de grande importância hídrica foram ou estão sendo degradadas. Não menos preocupantes são a miséria e o atraso cultural que vive boa parte da população de algumas regiões. Até o momento não se encontrou uma forma eficiente de melhorar as condições socioeconômicas de boa parte da população. Principalmente do médio Vale do Ribeira, uma das regiões mais belas e ricas em termos de recursos naturais e, por outro lado, uma das mais pobres e atrasadas dos estados de São Paulo e Paraná. 
Em relação à ocupação humana, o Vale do Ribeira passou por ciclos de exploração do ouro, implantação da agricultura de produtos para consumo e para o mercado local, desenvolvimento da lavoura de chá e de banana, sendo que esta última passou a ser o principal produto agrícola da região. A mineração de areia e calcário completa o quadro econômico da região.

O Vale do Ribeira é a região do Estado de São Paulo onde se encontra a maior parte das comunidades quilombolas e abriga também várias comunidades tradicionais e locais, indígenas, caiçaras e agricultores familiares (SANTOS; TATTO, 2008). Entretanto, a ocupação das terras de algumas comunidades ainda passa por conflitos, devido à falta de regularização fundiária ou sobreposição com UCs, que de acordo com o Sistema Nacional de Unidades de Conservação (SNUC), significa:

espaço territorial e seus recursos ambientais, incluindo as águas jurisdicionais, com características naturais relevantes, legalmente instituído pelo Poder Público, com objetivos de conservação e limites definidos, sob regime especial de administração, ao qual se aplicam garantias adequadas de proteção (Art. 2º , I - Lei Federal 9.985/2000).

Na década de 1980, o Estado de São Paulo criou a maioria das UCs da região, delimitando áreas para proteção dos ecossistemas, preservação da biodiversidade, apoio a pesquisas que garantam o aproveitamento dos recursos naturais e também propicie a educação ambiental, o turismo e o lazer nas áreas passíveis de visitação pública (SÃO PAULO, 1999).

Diante desse quadro, o ecoturismo desponta como potencial atividade econômica que alie o desenvolvimento social à preservação da natureza.

Romão (2006, p.21) argumenta que:

torna-se importante dar a base para uma forma de inserção da população do Vale do Ribeira em atividades que garantam sua existência e sobrevivência, tendo como aliado o interesse humano pelo legado natural, cultural e étnico da região, buscando melhorar as condições de vida sem alterar o modo de vida das comunidades tradicionais. A alternativa é dada pelo ecoturismo compreendido como uma atividade complementar àquelas realizadas pelas comunidades.

E concomitantemente, apontada na Agenda Socioambiental pelas comunidades quilombolas do Vale do Ribeira, o ecoturismo é indicado como importante atividade a ser aprimorada em suas áreas, conjugando os atrativos naturais com especial beleza cênica, tais como cachoeiras, rios e cavernas, com as características tradicionais de suas comunidades, como artesanato, culinária e formas de cultivo, resultando em atividade economicamente viável para desenvolvimento da população (SANTOS; TATTO, 2007). 
Koga, E.S.; Oliveira, C.S.; Kaneshiro, D.M.

\section{Ecoturismo}

O termo ecoturismo foi usado pela primeira vez por Héctor Ceballos-Lascurain, para designar viagens a áreas naturais relativamente preservadas como o intuito de lazer, educação ou o simples ato de admirar a paisagem ou uma manifestação cultural. O conceito evoluiu ao longo do tempo colocando o homem mais próximo e responsável pela natureza e pelas atividades exercidas no meio natural (KINKER, 2012).

O ecoturismo é um dos segmentos de turismo que mais se desenvolve nos últimos anos, impulsionado principalmente pelos movimentos ambientalistas e pela necessidade de se buscar alternativas econômicas que visem o desenvolvimento sustentável. Conceitualmente ecoturismo pode ser entendido como:

segmento da atividade turística que utiliza, de forma sustentável, o patrimônio natural e cultural, incentiva sua conservação e busca a formação de uma consciência ambientalista através da interpretação do ambiente, promovendo o bem-estar das populações (MICT; MMA, 1994).

Este segmento tem como princípios o desenvolvimento sustentável, a educação ou conscientização ambiental e o envolvimento das comunidades locais. Esses princípios garantem a sustentabilidade da atividade e caracterizam o ecoturismo por pautar o comportamento do turista em princípios e valores éticos, incorporando assim o conceito da sustentabilidade e o aspecto educacional (KINKER, 2012).

Portanto, o ecoturismo caracteriza-se pelas práticas de atividades de lazer, recreação, resgate histórico-cultural, contemplação e educação ambiental em áreas naturais não degradadas, utilizando como recurso principal as UCs.

O conceito de UC surgiu nos Estados Unidos, quando foi criada a primeira área natural protegida com o Yellowstone National Park, em 1 de março de 1872. No Brasil, a primeira UC criada foi o Parque Nacional do Itatiaia, em 1937, instituído através do Código Florestal de 1934 (COSTA, 2002).

Em 2000, a partir da compilação e revisão dos diversos marcos legais que instituíam as UCs, foi aprovada a Lei no 9.985 , instituindo o Sistema Nacional de Unidades de Conservação (SNUC) que, dentre as suas atribuições legais, deve "favorecer condições e promover a educação ambiental, a recreação em contato com a natureza e o ecoturismo" (Capt. II, Art. 4으, XII).

A importância de se definir as diretrizes do uso público nas UCs pauta-se na necessidade de organização e manejo das atividades dentro da UC e na possibilidade de geração de renda contribuindo para a proteção e fiscalização da própria unidade. Registros sobre a visitação pública em UC demonstram queda nas atividades extrativistas realizadas com a finalidade de geração de renda. Lindberg e Hawkins (2002, p. 23) sugerem "procurar pontos em comum entre o ecoturismo, a conservação e o desenvolvimento", e encontrar formas sustentáveis de minimizar os impactos negativos e potencializar os positivos. 
Programa de capacitação do Projeto de Ecoturismo na Mata Atlântica no entorno dos parques estaduais paulistas

\section{Planejamento participativo}

O planejamento participativo pressupõe o envolvimento de todos os membros interessados e/ou afetados pela tomada de decisão em torno de uma problemática. Nesse sentido o planejamento do fenômeno turístico deve ter como premissa a gestão integrada dos recursos e potencialidades turísticas da localidade. Para Rabinovici e Pessoa (2010)

visto que o turismo é uma atividade econômica que interfere na organização dos espaços, é necessário controle por parte dos governos e da própria comunidade na qual os projetos de turismo estão inseridos. $\mathrm{Pa}$ ra tanto a participação comunitária no planejamento não consiste apenas em receber passivamente os benefícios da atividade turística, mas sim intervir na sua condução, planejamento e implantação, que pode ser realizada por meio da participação de todos os envolvidos com o turismo na tomada por decisões (RABINOVICl; PESSOA, 2010. p. 112).

Tendo como pressuposto de que toda política publica deve ter em sua concepção e elaboração a participação de todos que possam vir a ser afetados com os programas e ações, projetos de desenvolvimento devem ter suas ações pautadas na participação cidadã, partindo de diretrizes sustentáveis e assumindo compromissos participativos. Assim, as políticas públicas tendem a garantir a sustentabilidade na continuidade do processo e nos impactos diretos dele decorrentes, mesmo que muitas vezes, não sejam passíveis de mensuração. Para Irving (2002), nesses projetos o envolvimento da sociedade nas tomadas de decisões são indispensáveis para que o processo atinja a sustentabilidade e legitimidade e seja intitulado como participativo.

O planejamento participativo se configura como uma importante ferramenta pra entender todas as dimensões de um problema, seja ele social, econômico ou ambiental. Portanto, entender o que de fato é planejamento participativo e como este deve ser executado pelo Estado é imprescindível para avaliar como foram implementadas as ações do Projeto de Ecoturismo.

$\mathrm{Na}$ gestão do ecoturismo em regiões de preservação ambiental, caso do Vale do Ribeira e Alto Paranapanema, há interesses diversos e muitas vezes divergentes que podem ocasionalmente gerar atritos entre os envolvidos. Diante deste cenário o planejamento participativo possibilita um questionamento mais amplo em torno da problemática e assim estender suas soluções. A aplicação do método pode ser usado como mecanismo de articulação entre os interessados e instrumento de legitimação da democracia.

No Brasil, há poucos registros de participação cidadã no desenvolvimento do turismo, Solha (2011) aponta que este fato se dá pela fragilidade das representações estaduais e municipais, devido a longa tradição de centralismo na qual as esferas do poder público a níveis regionais e locais só eram vistas como cumpridoras das regras estabelecidas pelo poder federal.

Entretanto, Molina e Rodriguez (2001) apresentam uma mudança significativa nos modelos de planejamento uma vez que: 
(...) o planejamento centralizado está cedendo lugar a um outro mais participativo, que reconhece as capacidades e interesses locais e regionais e as realidades dos grupos humanos e econômicos que atuam em suas respectivas áreas (MOLINA: RODRIGUEZ, 2001, p.14).

Nesse sentido, Back (2009) aponta que os projetos turísticos devem caminhar para um planejamento descentralizado, num processo democratizado que contempla não só o desenvolvimento econômico como também o desenvolvimento da comunidade e o respeito pelo meio ambiente.

Para Sansolo (2006), a partir da Constituição de 1988, ficou mais clara a necessidade de desenvolvimento de planos pulirianuais e regionalizados, com processo participativo em sua concepção. Para o autor, o marco para a gestão participativa foi a Agenda 21 Global, elaborada durante a Conferência das Nações Unidas sobre Meio Ambiente e Desenvolvimento - Rio 92. Este documento tornou-se referência para todas as esferas governamentais e contribuiu para a popularização do paradigma da participação.

Entretanto, o planejamento participativo colocado em prática pode apresentar distorções quando as ideias ou problemas e decisões tomadas por lideranças nem sempre são representativas da comunidade como um todo e que muitas vezes podem atender aos interesses pessoais dessas lideranças. Outra dificuldade encontrada no uso do planejamento participativo é a incapacidade das estruturas de poder e burocráticas em incorporar as decisões tomadas de "baixo para cima" (SANSOLO, 2006).

Portanto trata-se de uma nova forma de articulação com os setores envolvidos, em que a capacidade de argumentação e criação de parcerias pode ser primordial na busca dos resultados do projeto.

Complementando este raciocínio, Sampaio et. al. (2010) afirma que o fortalecimento e o envolvimento das comunidades no âmbito de instâncias coletivas de participação, como conselhos e fóruns de desenvolvimento, podem se configurar como importante instrumento para o desenvolvimento local integrado e sustentável.

Em Unidades de Conservação (UCs) a prática do planejamento e gestão participativa é mais comum e mais difundida. Como a exemplo do funcionamento dos Conselhos Gestores das UCs, onde além do Gestor da unidade, diversos conselheiros que representam instituições, segmentos e comunidades externas da UC, atuam no planejamento das atividades, nas discussões e decisões acerca da área.

São princípios gerais sobre os processos de gestão participativa em UCs, apontados por Rabinovici e Pessoa (2010):

- Compartilhar as responsabilidades, buscando a melhor proteção da UC;

- Estabelecer uma relação entre a UC e seu entorno;

- Motivar a participação comunitária;

- Conhecer e respeitar a cultura da população;

- Melhorar a qualidade das ações na gestão de UCs; 
Programa de capacitação do Projeto de Ecoturismo na Mata Atlântica no entorno dos parques estaduais paulistas

- Garantir o acesso à informação;

- Garantir a equidade social;

- Melhorar a eficiência na gestão das UCs.

Diante dessas possibilidades, a gestão das áreas naturais protegidas devem calcar suas ações em processos participativos, legitimando as estratégias de desenvolvimento e preservação do meio ambiente em consenso social, promovendo também o envolvimento dos diversos atores como responsáveis e parceiros na gestão da UC e seus resultados.

Para alcançar efetivamente os objetivos estabelecidos no programa de capacitação do Projeto de Ecoturismo na Mata Atlântica, foi primordial a participação dos envolvidos de forma comprometida, responsável e protagonizada. E para atingir esse comprometimento, o Núcleo de Apoio à Cadeia Produtiva do Turismo do Projeto desenvolveu um processo participativo para consolidar um plano estratégico de capacitação comunitária.

O processo deu início com a realização de oficinas de planejamento participativo com a finalidade de mobilizar os interessados, levantar as demandas por cursos e quantidade de interessados, envolvendo comprometidamente os grupos de interesse para garantir a continuidade integrada deste plano.

As oficinas seguiram os princípios do enfoque participativo, com ênfase no intercâmbio de experiências e conhecimentos, tendo como ferramentas metodológicas a visualização, apresentações, problematização, documentação, trabalhos em grupos, sessões plenárias, contando com o apoio de um moderador.

As oficinas ocorreram em outubro de 2008 nas sedes dos Parques Estaduais "Carlos Botelho", Intervales, Caverna do Diabo e Turístico do Alto Ribeira - PETAR e participaram cerca de trinta comunidades que vivem no entorno dos parques, somando mais de 130 pessoas.

Buscando nivelar os conceitos entre os participantes, o moderador iniciou um bloco abordando o turismo integrado com as comunidades e Unidades de Conservação, em visão de trocas e de potencialização da atividade turística. Esta etapa teve o objetivo de levar os participantes a refletir sobre as atividades ligadas ao turismo e que acontecem nas áreas de influência. A identificação destas atividades permitiu, mais facilmente, a definição das grandes áreas para capacitação comunitária. Ainda foram orientados a identificar, em mapas, a localização exata de realização destas atividades.

A partir das atividades identificadas na etapa anterior, os participantes, em plenário, definiram as áreas gerais de capacitação: Monitoria Ambiental, Hospitalidade, Produtos da Roça/Floresta, Produtos Culturais, Manejo Sustentável, Fortalecimento de Organizações/Comunidades e Planos de Negócio. Além dessa indicação, os participantes elaboraram uma matriz de capacitação, seguindo três campos orientadores: tipo de capacitação, parceiros e data/local (indicativos). 
Koga, E.S.; Oliveira, C.S.; Kaneshiro, D.M.

\section{Resultados alcançados}

O programa de qualificação foi composto em três grandes grupos, conforme já citados anteriormente a fim de fortalecer os segmentos da região do entorno dos Parques. Para cada grupo, foi realizada a contratação de uma empresa/instituição para incrementar a capacitação, buscando a experiência e conhecimento nos assuntos tratados.

A seguir, relata-se os resultados obtidos em cada um dos segmentos.

\section{Capacitações comunitárias}

Para as capacitações comunitárias, foram oferecidos cursos em dez temas: Aperfeiçoamento de monitores ambientais, Artesanato tradicional, Gestão de projetos, Organização institucional, Elaboração de plano de manejo agroflorestal, Plano de negócios institucional, Plano de negócios de artesanato, Plano de negócios para produtos agroflorestais, Coleta de sementes e Apicultura e meliponicultura (Figura 1). As capacitações foram executadas pelo Instituto Socioambiental (ISA), contratado através de licitação, no período de janeiro a julho de 2011.

O processo de mobilização para as capacitações comunitárias superou as dificuldades na região de comunicação, carente de sistemas instalados de antenas, de rede elétrica ou até mesmo de estradas de difícil circulação e conseguiu ter abrangência devido ao forte envolvimento das instituições, grupos e lideranças comunitárias que atuam na região. A contratação de empresa com experiência em projetos anteriores na região e conhecimento das comunidades tradicionais foi primordial para o bom resultado da mobilização. E o processo conjunto de interessados também foi importante para proporcionar melhor integração e intercâmbio entre os participantes.

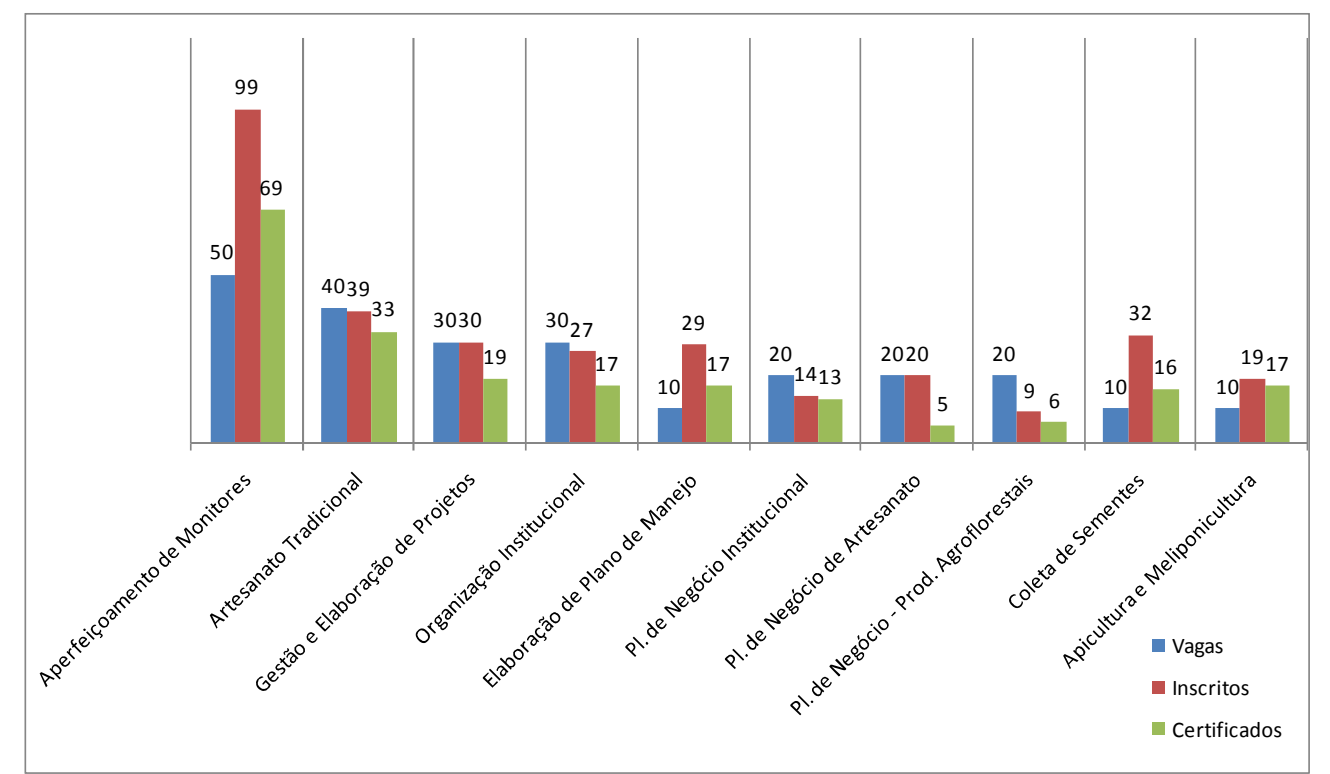

Figura 1: resultados das capacitações comunitárias por módulo.

Figure 1: results of community capabilities per module. 
Programa de capacitação do Projeto de Ecoturismo na Mata Atlântica no entorno dos parques estaduais paulistas

Finalizados os cursos, os resultados obtidos foram: 323 inscrições realizadas, 46 módulos ministrados, 212 pessoas certificadas, 32 comunidades envolvidas de 8 municípios diferentes. Os números refletem o interesse das comunidades em qualificar suas atividades para desenvolvimento regional e incremento da cadeia produtiva.

A capacitação abrangeu também pessoas que atuavam em atividades extrativistas ilegais em áreas protegidas e buscam novas alternativas econômicas, como o ecoturismo.

Os cursos foram, em sua maioria, sediados dentro dos Parques Estaduais, propiciando a visitação das populações que vivem na região e que ainda não haviam visitado as Unidades de Conservação. As atividades propiciaram aproximação entre os gestores dos parques e funcionários com as populações da região.

Alguns cursos tiveram inscrições e certificações superiores ao número de vagas ofertadas, como aperfeiçoamento de monitores, elaboração de plano de manejo, coleta de sementes e apicultura e meliponicultura.

Embora alguns cursos foram realizados no período e alta temporada e o tempo de divulgação e mobilização foram curtos, a taxa de certificação atingiu $67 \%$, ou seja, um bom percentual de alunos que se inscreveu e aproveitou os cursos até o fim.

\section{Capacitações dos gestores municipais}

Os cursos voltados para os gestores municipais de turismo e/ou meio ambiente tiveram como temáticas: Aula Inaugural e Conceitos Básicos de Turismo, Turismo e Meio Ambiente em UCs, Planejamento Estratégico e Elaboração de Projetos. A capacitação foi ministrada entre julho e agosto de 2010 pela empresa Manufatura de Ideias, vencedora da licitação pública.

Em fase preparatória para as inscrições, os consultores da empresa contratada juntamente com a equipe do Núcleo de Apoio à Cadeia Produtiva do Turismo do Projeto de Ecoturismo reuniu-se com cada um dos responsáveis nas Prefeituras para apresentar a proposta de capacitações, com o objetivo de levantar o número de participantes, agendas e compromissos e, especialmente, temáticas a serem alinhadas durante os cursos.

Passada a fase inicial, as inscrições ocorreram de forma espontânea, abrindo duas vagas para cada município, com agenda proposta de quatro encontros com duração de dois dias cada, nos seguintes locais: Pousada comunitária em Ivaporunduva, Parque Estadual Carlos Botelho, Parque Estadual Intervales e PETAR.

Os encontros proporcionaram diversos resultados: integração de gestores públicos de turismo e meio ambiente de região com características em comuns, inclusive em relação a problemas e soluções; imersão durante dois dias que favoreceram a capacitação e também a troca de conhecimentos e integração nos horários fora dos cursos; e, vivência dentro de comunidades e nos Parques Estaduais discutindo propostas de desenvolvimento do turismo especialmente nessas localidades.

Ao fim dos cursos, realizou-se quatro encontros em dois meses, com a partici- 
Koga, E.S.; Oliveira, C.S.; Kaneshiro, D.M.

pação de 32 gestores públicos municipais, atuantes em 16 Prefeituras das regiões do Vale do Ribeira, Alto Paranapanema e Ilhabela.

\section{Capacitações aos micro e pequenos empresários de turismo}

Os módulos oferecidos para a iniciativa privada foram: Cenário Atual do Turismo, Atendimento ao Cliente, Primeiros Socorros, Atividades Recreativas, Gestão de Turismo, Serviços de Alimentos e Bebidas (A\&B), Noções de Meios de Hospedagem $(\mathrm{MH})$, Gestão de Alimentos e Bebidas e Gestão de Meios de Hospedagem (Figura 2). Os cursos foram ministrados pelo SENAC durante o período de agosto de 2010 e agosto de 2011.

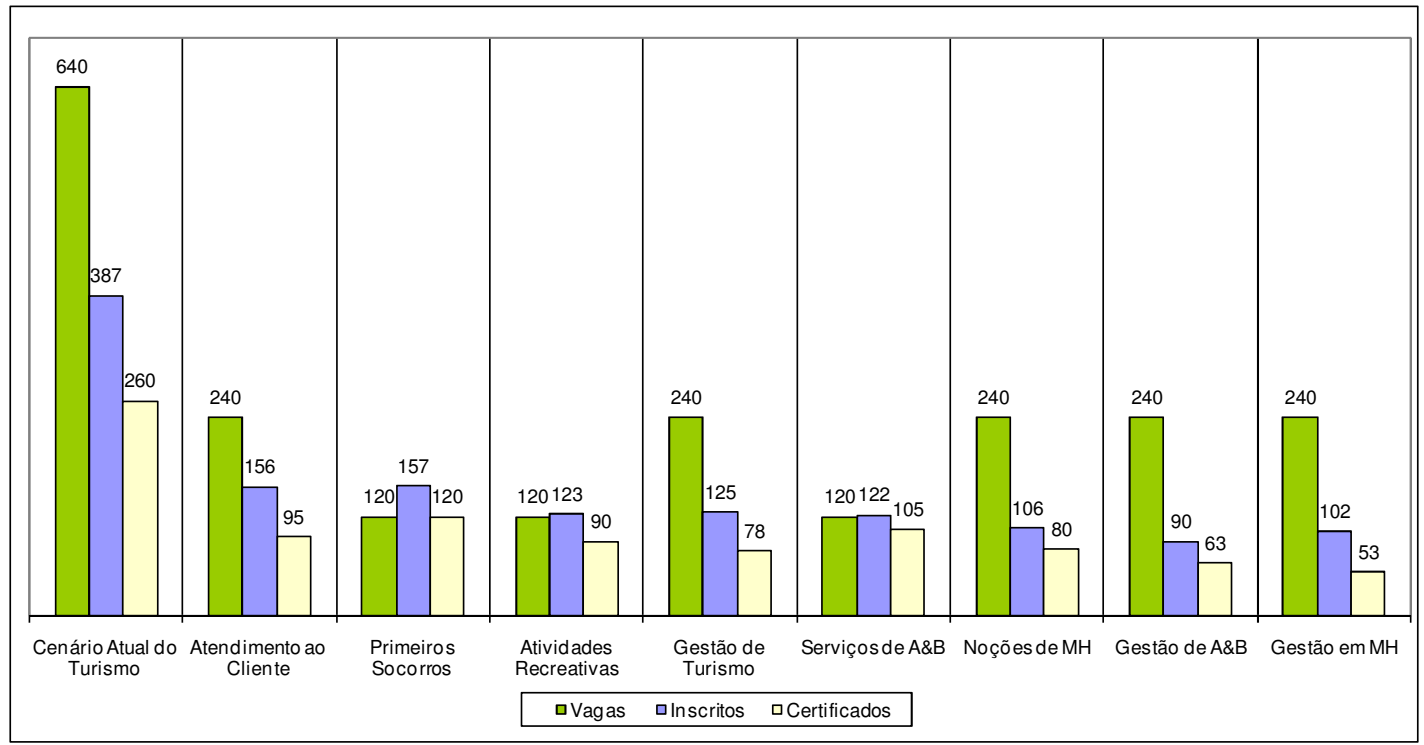

Figura 2: resultados capacitações empresários por módulo.

Figure 2: Results for entrepreneurs training module.

Os cursos foram ministrados por Pólo de Ecoturismo, formado em função dos municípios com território contido dentro dos Parques Estaduais. Essa regionalização foi organizada pelo Grupo Gestor da Cadeia Produtiva, fruto de uma consultoria contratada pela Fundação para o Desenvolvimento das Artes e da Comunicação - FUNDAC.

O objetivo para a delimitação inicial destes Pólos Ecoturísticos foi estabelecer uma hierarquia territorial para a continuidade do Projeto de Desenvolvimento do Ecoturismo na Região da Mata Atlântica, para que, através das ações de organização da atividade turística, construa-se uma "cadeia de valores" capaz de articular pouco a pouco outras comunidades do Vale do Ribeira, Alto Paranapanema e do entorno da llhabela.

Como atividade que fortalece a organização dos Pólos de Ecoturismo, as capacitações aos micro e pequenos empresários contribuiram para reunir as pessoas du- 
Programa de capacitação do Projeto de Ecoturismo na Mata Atlântica no entorno dos parques estaduais paulistas

rante os módulos, a fim de que as discussões abrangessem a região, e não apenas o município.

Ao final desse segmento de capacitações, foram ministrados 64 módulos distribuídos entre os seis Pólos de Ecoturismo. A oferta de 2.000 vagas gratuitas obteve a inscrição de 1.368 pessoas e a conclusão de 944 profissionais.

O resultado de $69 \%$ de certificação, que mede o percentual de concluintes sobre o número de inscritos foi satisfatório, atendendo um nível de qualidade dos cursos ministrados.

Verificou-se que o envolvimento da iniciativa privada no processo de qualificação do ecoturismo na região do entorno dos Parques Estaduais é um importante aliado para a formação de uma cadeia de atividades relacionadas à atividade turística.

\section{Considerações finais}

O processo de planejamento e organização de uma destinação turística requer a participação e envolvimento de diversos grupos interessados, com empenhos e conveniências distintas.

O ecoturismo, por ser uma atividade que exige peculiaridades em sua forma de atuar, envolve pessoas com características especiais, em áreas de cuidados adicionais, entre outras especificidades, requer qualificação constante e discussão permanente voltados para a evolução de um turismo responsável.

O processo participativo se faz essencial para enrijecer o protagonismo dos principais envolvidos nas atividades de ecoturismo, sejam os gestores dos Parques Estaduais, os gestores municipais, os profissionais das atividades de turismo ou as comunidades tradicionais. A integração requer uma iniciativa organizada e democráti$\mathrm{ca}$, de forma a garantir o envolvimento mais abrangente possível.

Os cursos almejaram o envolvimento entre diversos segmentos, formatação de novas parcerias e dar força à região do entorno dos Parques Estaduais como destino para visitação. Identificada como prioridade para o desenvolvimento da região, a capacitação das pessoas envolvidas com a visitação e o uso público das áreas naturais protegidas devem ser aprimoradas e adaptadas às realidades sociais dos envolvidos.

O Projeto de Desenvolvimento do Ecoturismo na região da Mata Atlântica é uma iniciativa do Estado de São Paulo, por intermédio da Secretaria do Meio Ambiente, que vislumbra a proteção da biodiversidade de suas UCs, atrelando atividades diretas e indiretas que apoiem a conservação. $O$ ecoturismo, enquanto atividade cautelosa em relação ao meio ambiente, pessoas e desenvolvimento econômico, ganha visibilidade nas discussões e diretrizes para seu aprimoramento dentro dos Parques Estaduais.

As atividades desenvolvidas no ensejo do Contrato de empréstimo junto ao BID servem de piloto para orientar o planejamento do ecoturismo dentro de áreas naturais protegidas e devem servir de estímulo para novos projetos e investimentos. 
Koga, E.S.; Oliveira, C.S.; Kaneshiro, D.M.

\section{Referências bibliográficas}

BACK, G. As coordenadas do turismo: Sistema de Informação Geográfica no planejamento turístico do núcleo Santa Virgínia do Parque Estadual Serra do Mar, São Paulo - SP. Dissertação de mestrado do Programa de Mestrado em Hospitalidade da Universidade Anhembi Morumbi. São Paulo: UAM, 2009.

BRASIL. Lei № 9.985, de 18 de julho de 2000. Institui o Sistema Nacional de Unidades de Conservação.

COSTA, P.C. Ecoturismo. São Paulo: Aleph, 2002.

COSTA, P.C. Unidades de Conservação: matéria prima do ecoturismo. São Paulo: Aleph, 2002.

CBH-ALPA. Relatório de Situação dos Recursos Hídricos da Bacia Hidrográfica do Alto Paranapanema - UGRHI 14. Piraju: 2011.

IRVING, M.A.; AZEVEDO, J. Turismo: o desafio da sustentabilidade. São Paulo: Futura, 2002.

KINKER, S. Ecoturismo e conservação da natureza em Parques Nacionais. Campinas - SP: Papirus, 2002.

LINDBERG, K.; HAWKINS, D.E. (Orgs). Ecoturismo: um guia para planejamento e gestão. 4ํㅜ ed. São Paulo: Editora Senac, 2002.

MOLINA E. Sérgio; RODRIGUEZ A. Sérgio. Planejamento integral do turismo. Bauru SP: EDUSC, 2001

OLIVEIRA, A. C. L; MATHEUS, F. S.; SANTOS, R. P.; BRESSAN, T. V. (Org.) Ecoturismo. São Paulo: SMA, 2010. (Cadernos de Educação Ambiental, 5)

ROMÃO, D.A. (Org.) Vale do Ribeira: um ensaio para o desenvolvimento das comunidades rurais. Brasília: Ministério do Desenvolvimento Agrário, 2006.

SAMPAIO, C.AC; PHILIPPI, A. Planejamento e gestão do turismo comunitário sustentável: metodologia PEC \& SIGOS. In: PHILIPPI, A.; RUSCHMANN, D. Gestão Ambiental e Sustentabilidade no Turismo. São Paulo: Manole, 2010.

SANSOLO, D.G. Centralismo e Participação na proteção da natureza e desenvolvimento do turismo no Brasil. In: IRVING, M.A. (Org). Áreas protegidas e inclusão social: construindo novos significados. Rio de Janeiro: Fundação Bio-Rio: Núcleo de Produção Editorial Aquarius, 2006.

SANTOS, K.M.P.; TATTO, N. Agenda socioambiental de comunidades quilombolas do Vale do Ribeira. São Paulo: Instituto Socioambiental, 2008.

SÃO PAULO, SECRETARIA DE ESTADO DO MEIO AMBIENTE DE SÃO PAULO. Conhecer para conservar: as unidades de conservação do Estado de São Paulo. São Paulo: Terra Virgem: Secretaria do Estado do Meio Ambiente, 1999. 
Programa de capacitação do Projeto de Ecoturismo na Mata Atlântica no entorno dos parques estaduais paulistas

SOLHA, K.T. O papel do Poder público para o turismo sustentável. In: PHILIPPI, A.; RUSCHMANN, D. Gestão Ambiental e Sustentabilidade no Turismo. São Paulo: Manole, 2011.

THEODOROVICZ, A. Atlas geoambiental: subsídios ao planejamento territorial e à gestão ambiental da bacia hidrográfica do rio Ribeira do Iguape. 2. Ed. São Paulo: CPRM, 2007.

Érika Sayuri Koga: Secretaria do Meio Ambiente do Estado de São Paulo, São Paulo, SP, Brasil

Email: erikask@ambiente.sp.gov.br

Link para o currículo Lattes: http://lattes.cnpq.br/0728595979334168

Caroline da Silva Oliveira: Secretaria do Meio Ambiente do Estado de São Paulo, São Paulo, SP, Brasil

Email: carolineso@ambiente.sp.gov.br

Link para o currículo Lattes: http://lattes.cnpq.br/1523793003113053

Daniela Midori Kaneshiro: Secretaria do Meio Ambiente do Estado de São Paulo, São Paulo, SP, Brasil

Email: danielamk@ambiente.sp.gov.br

Link para o currículo Lattes: http://lattes.cnpq.br/0728595979334168

Data de submissão: 29 de junho de 2012

Data de recebimento de correções: 14 de dezembro de 2012

Data do aceite: 14 de dezembro de 2012

Avaliado anonimamente 